IZA DP No. 5141

Location Choices of Migrant Nest-Leavers:

Spatial Assimilation or Continued Segregation?

Aslan Zorlu

Clara H. Mulder

August 2010 


\title{
Location Choices of Migrant Nest-Leavers: Spatial Assimilation or Continued Segregation?
}

\author{
Aslan Zorlu \\ AISSR and AIAS, University of Amsterdam \\ and IZA \\ Clara H. Mulder \\ AISSR, University of Amsterdam \\ Discussion Paper No. 5141 \\ August 2010 \\ IZA \\ P.O. Box 7240 \\ 53072 Bonn \\ Germany \\ Phone: +49-228-3894-0 \\ Fax: +49-228-3894-180 \\ E-mail: iza@iza.org
}

Any opinions expressed here are those of the author(s) and not those of IZA. Research published in this series may include views on policy, but the institute itself takes no institutional policy positions.

The Institute for the Study of Labor (IZA) in Bonn is a local and virtual international research center and a place of communication between science, politics and business. IZA is an independent nonprofit organization supported by Deutsche Post Foundation. The center is associated with the University of Bonn and offers a stimulating research environment through its international network, workshops and conferences, data service, project support, research visits and doctoral program. IZA engages in (i) original and internationally competitive research in all fields of labor economics, (ii) development of policy concepts, and (iii) dissemination of research results and concepts to the interested public.

IZA Discussion Papers often represent preliminary work and are circulated to encourage discussion. Citation of such a paper should account for its provisional character. A revised version may be available directly from the author. 
IZA Discussion Paper No. 5141

August 2010

\section{ABSTRACT \\ Location Choices of Migrant Nest-Leavers: Spatial Assimilation or Continued Segregation?}

We examine ethnic differences in the ethnic composition of the destination neighbourhood upon leaving the parental home using administrative data for the entire birth cohort 1983 living in the Netherlands. The analysis provides little evidence of a clear intergenerational break in the location choices of young men and women from a non-western origin compared to their parents. The neighbourhood choice pattern of those who leave the parental home for independent and shared living arrangements does not differ markedly from that of their parents, while nest-leavers for union formation are more likely to move to neighbourhoods with a relatively small proportion of non-western inhabitants. A decomposition analysis indicates that an overwhelmingly large part of neighbourhood choice is explained by differences in background variables. Particularly, the origin neighbourhood type of nestleavers seems to be a driving force underlying the choice of destination neighbourhood, given individual and parental socioeconomic characteristics.

JEL Classification: J15, J61

Keywords: migrants, spatial assimilation, leaving home

Corresponding author:

Aslan Zorlu

Amsterdam Institute for Social Science Research (AISSR)

University of Amsterdam

Nieuwe Prinsengracht 130

NL-1018 VZ Amsterdam

Netherlands

E-mail: A.Zorlu@uva.nl 


\section{1, Introduction}

For a number of decades, substantial immigration waves have entered the Netherlands. Most if these immigrants either came from Turkey and Morocco, or from Surinam and the Dutch Antilles. Turkish and Moroccan immigrants responded to the large labour shortages in the lower segment of labour market that emerged in the post-World War II period. Immigration from Surinam and the Dutch Antilles was an outcome of colonial relationships between the Netherlands and these countries. In the 1980s, the family members of earlier immigrants dominated the inflow of new immigrants. When immigration flows driven by family reunification began to fade away, a massive number of asylum seekers have knocked the door in the 1990s, in addition to brides and bridegrooms of previous labour migrants and their descendents.

Traditionally, immigrants tend to concentrate in certain neighbourhoods of large cities in the host countries. The largest immigrant groups that currently populate concentration neighbourhoods in large cities started to come to the Netherlands in the 1960s and the 1970s. The first immigrants were attracted by the supply of affordable housing in old city neighbourhoods. Subsequently, new immigrants followed their co-ethnics. Growing immigrant communities in certain neighbourhoods generated their own ethnic social networks and produced ethnic goods and services. This development has reinforced, in turn, ethnic residential segregation. Over time, a shift of concentration areas has taken place from old city centres to newer neighbourhoods constructed in the 1960s. However, ethnic residential segregation is still associated with socioeconomic disadvantages and poor future prospects. Public policy has therefore declared ethnic residential segregation as an undesirable outcome of selective migration processes in the Netherlands. The current administration has even created a new ministry to combat the segregation effectively.

Nowadays, a significant proportion of immigrant groups in the Netherlands is composed of the children of the original migrants, the so-called second generation. On average, the socioeconomic position of immigrants and second-generation immigrants has improved significantly. An increasing number of studies show that the performance of immigrants has increased with duration of stay. The second generation is better educated than their parents, which leads to direct rewards in the labour market (Zorlu \& Hartog, 2008). As posited by spatial assimilation theory (Massey, 1985), a decreasing socio-economic distance between an immigrant group and the majority population is expected to lead to a decline in spatial distance between these groups. A recent study suggested that a general process of spatial assimilation has not started yet for non-western migrants, although there is some modest evidence of a spatial diffusion of Surinamese and Antilleans. Turkish and Moroccan migrants, in contrast, tend to move to neighbourhoods with larger concentrations of nonwestern immigrants (Zorlu \& Latten, 2009).

Leaving home is an important occasion for youth from migrant families either to continue living in segregated neighbourhoods or to break with their parents' tendency to segregate. Whereas some migrant youth may prefer to stay near their family upon leaving home, educational or labour-market opportunities may lead others to move away and leaving home might be an occasion for starting to deviate from the parental tradition. The location choices of nest-leavers may therefore play an important part in the spatial assimilation of nonwestern migrants and their descendants.

This paper focuses on the spatial mobility of youth from non-western migrant families who leave the parental home. 'Non-western' refers to immigrants from Africa, Latin America, and Asia with the exception of Indonesia and Japan. For convenience, young adults from 
migrant families are denoted as 'migrant youth' or 'migrants', even though only some of them actually migrated with their parents. A larger share was born in the Netherlands from at least one foreign-born parent. In the life course of these migrant youth, leaving home is possibly a critical time to leave an immigrant neighbourhood where their residence was determined by their parents. When they decide to leave the parental home, they can simultaneously choose their new neighbourhood within the limits of financial restrictions. We examine whether, upon leaving home, there is an intergenerational break in the location choices of migrant youth compared to their parents. Besides the potential role of leaving home in the spatial assimilation of migrant youth, there is another reason for studying their location choices. Regardless of location choice, leaving the parental home is an important step towards independence in the life course. But spatial flexibility in location choice is crucial to young people's opportunities for enrolment in higher education and for gaining spatial access to jobs (Mulder \& Clark, 2000). Despite this importance of location choice, it has not been addressed in the scarce literature on leaving home among youth from migrant families (Bernhardt et al., 2007, Nilsson and Strandh, 1999 for Sweden; Bolt, 2002, De Valk and Billari, 2007, Zorlu \& Mulder, forthcoming, for the Netherlands; Glick and Van Hook, 2002 for the United States).

The analysis in this paper follows an earlier analysis of leaving home of Dutch and various migrant groups (Zorlu \& Mulder, forthcoming). The research question is: How do the location choices of non-western migrant nest-leavers with respect to the ethnic composition of the neighbourhood differ from those of native Dutch, and to what extent can these differences be explained by characteristics of the individual, the parents and the origin neighbourhood? To address this question, we use unique individual administrative panel data for the entire birth cohort 1983 for the period 1999-2005, derived from the Social Statistical Database (SSD) housed by Statistics Netherlands. The panel dimension of these rich data allows us to identify individual socio-economic positions, whether people move, and characteristics of the origin and destination neighbourhoods of potential movers, including the degree of concentration of immigrants. We employ descriptive techniques and regression analysis to assess differences in the ethnic composition of the destination neighbourhood of nest-leavers. Subsequently, we decompose the differences in the ethnic composition of the destination neighbourhoods of Dutch and migrants into two components. The first component refers to the contribution of observed characteristics included in the regression models, while the second component refers to the contribution of unobserved factors such as preferences and discrimination.

Given the sharply decreasing immigration from the main origin countries, the spatial mobility of immigrants and their descendants within the host country is now more important to segregation tendencies than the location choices of newly entering immigrants. The results of the analysis will therefore have a strong predictive power for the future of ethnic residential segregation dynamics in the Netherlands.

\section{Theoretical background}

\subsection{Spatial assimilation}

Spatial assimilation theory, originally designed to study the mixing process of European immigrants and the native-born population in the United States in the early $20^{\text {th }}$ century, suggests that immigrants initially settle in enclaves, mainly to utilise the advantages of ethnic networks (Gross \& Massey, 1991; Massey, 1985; Massey \& Denton, 1985). As they learn the dominant language and improve their socio-economic position, they begin to move to neighbourhoods with a higher level of economic prosperity, where the native-born population is usually the dominant group (Alba \& Logan, 1993). Such proximity facilitates more contact with the native-born population and accelerates the adjustment of immigrants 
into the host society. The incorporation process of European immigrants to the United States developed along these lines: a spatial dispersion from the initial enclaves mirrored the declining socioeconomic distance and increasing language proficiency as their time in the host country elapsed.

Spatial assimilation theory also implies that similarities between the host society and an immigrant group can reflect the settlement pattern of this immigrant group and the rate of decrease in the spatial distance with time. Similarities with the majority population are generally approximated by human capital endowment, proficiency in the local language, and religion. Immigrants with a smaller cultural and linguistic distance are less likely to settle initially in ethnically segregated areas. In addition, their spatial distance will decrease more quickly if they initially settled in immigrant neighbourhoods, for example owing to a weak economic position.

Although spatial assimilation theory predicts an increasing proximity of immigrants to the native population as a result of improvement in their socioeconomic position, recent empirical evidence suggests that social mobility does not necessarily lead to spatial assimilation. This appraisal led to a modification of the classical assimilation model, often referred to as segmented assimilation. Comparing assimilation trajectories of immigrants from Europe and newer immigrants from mid- and Latin America in the United States, Portes and Zhou (1993) suggest that children of more recent immigrants do not necessarily fully assimilate into mainstream society. One of the possible trajectories is downward social and economic mobility, in which an immigrant group ends up as an urban underclass over time. According to the segmented assimilation model, children from certain non-white immigrant groups may not have access to the middle-class white society, no matter how acculturated they become, and consequently tend to remain in their own ethnic community. Other groups of immigrant children may choose a selective assimilation strategy: adopting some aspects of the mainstream society while maintaining strong ties with their own ethnic community in other areas.

The segmented assimilation model was developed to understand socioeconomic assimilation of immigrants in the United States. It has recently been applied to the spatial distribution of blacks and ethnic groups from Hispanic and Asian origin. An implication of this more general framework is that the spatial assimilation of some newer immigrant groups will decline, rather than increase, across successive generations. Empirical evidence suggests that various Hispanic origin groups experience different spatial mobility and concentration patterns, and that such patterns do not necessarily reflect differences in human capital endowment and proficiency in English. For instance, Porto Ricans are more segregated than Mexicans. Another striking case is Cubans who are more likely to congregate in communities than Mexicans although their socioeconomic status is higher (South et al., 2005). These differences in spatial mobility can arise from differences in preferences and discrimination. We are not aware of applications of the segmented assimilation model in European countries.

\subsection{Ethnicity and location choice}

In the Netherlands and many other western countries, concentration neighbourhoods of non-western migrants are often concentration locations of disadvantaged people. A large number of studies, however, show that the socio-economic position of individual households and local housing-market conditions explain only a fraction of ethnic segregation (Zorlu \& Latten, forthcoming; Musterd, 2005; Van Kempen \& Ozuekren, 1998; Cutler et al., 1999). Discrimination and preferences have been often mentioned as two major factors to explain the emergence and persistence of segregated neighbourhoods. Empirical evidence on the role of 
preferences and discrimination mainly comes from US studies (Farley et al., 1978, 1994; Galster, 1990; Clark, 1991, 1992; South \& Crowder, 1997). US-based research has provided evidence that differences in preferences have certainly been influential in neighbourhood racial and ethnic transitions, even after accounting for other segregating forces such as individual and family-level socio-economic and demographic variables and non-ethnic neighbourhood characteristics (Card et al., 2008; Schelling, 1971; Zhou \& Logan, 1991).

In European research, little attention has been paid to the role of discrimination in segregation tendencies. European research suggests that the relatively weak economic status of migrants together with local housing market structures is responsible for a large part of ethnic residential segregation. In addition, ethnic segregation is often attributed to cultural differences, given the socioeconomic status of migrants (Musterd \& De Vos, 2007; Musterd, 2005; Simpson, 2004; Van Kempen \& Ozuekren, 1998).

Although preferences to live close to co-ethnics might be central to spatial segregation, there is another dimension of ethnic preferences. Beyond ethnicity, the rather strong family ties of disadvantaged ethnic minorities seem to play an important role in preferring to live in ethnically segregated area. The separate contribution of family ties has been often ignored and been seen as just a part of ethnic ties. Recent studies show that family ties keep disadvantaged people residing in the vicinity of family members and effectively prevent them from leaving segregated neighbourhoods (Spilimbergo \& Ubeda, 2004; Dawkins, 2006; Zorlu, 2008). By focusing on nest-leavers, we study a population that is homogenous with regard to the presence of parents because all nest-leavers have their parents in the origin neighbourhood by definition. The focus on those who leave home also has another advantage: we are dealing with a category of young adults who are similar in the sense that they have secured the resources necessary to start an independent household and have overcome potential parental pressure to remain at home.

We expect youth from non-western migrant families to be more likely to move to neighbourhoods with large percentages of non-western migrants than native Dutch and western migrants. This should hold even after accounting for the percentage of nonwesterners in the origin neighbourhood: many nest-leavers will simply stay close to their parental homes and will therefore end up in neighbourhoods with similar percentages of nonwesterners. Therefore, a positive association is expected between the percentages nonwesterners in origin and destination neighbourhoods.

Additionally, we expect youth with ethnic origins that are culturally or linguistically close to the Dutch to be more likely to assimilate spatially than other non-western migrant youth. This holds particularly for Surinamese and Antillean youth: because of the colonial history even those arriving at adult ages usually speak Dutch as their first or second language. Their religious background is also less different from that of the Dutch. Turkish, Moroccan and part of the other non-western migrants, in contrast, have a Muslim background and firstgeneration migrants hardly ever speak Dutch upon arrival in the Netherlands. In the same vein, we expect second-generation migrant youth, and particularly those of mixed ethnic background, to move to neighbourhoods with fewer non-westerners than those who immigrated with their parents.

\subsection{Other factors influencing location choices of nest-leavers}

Location choices of nest-leavers are determined by many other factors than preferences for a certain ethnic composition. Because neighbourhoods with many nonwestern inhabitants are nearly always also those with inexpensive housing, it is important to account for the individual socio-economic position of the young adults and their parents. We 
expect those with more resources - the employed, those with higher individual and parental incomes, those living in owner-occupied and more expensive housing before moving out - to move to neighbourhoods with fewer non-western inhabitants. Many of those still enrolled in education probably leave home to live near a college or university. As students, they will look for cheap accommodation, part of which is found in neighbourhoods with many non-western inhabitants.

Location choice is likely also associated with the pathway chosen upon leaving home - to live alone, to form a union, or to live in shared accommodation. Those forming a union are likely to have more resources, because they can pool them with their partner. Furthermore, their households are larger and they are more likely to anticipate forming families, and thus to prefer larger homes in a child-friendly environment. These homes and environments are found more easily in neighbourhoods with smaller percentages of non-westerners. It should be noted that the pathway of leaving home is likely partly endogenous to location choice and that any associations we find cannot be interpreted as strictly causal. The parental household situation may also play a part in location choice. Unmarried parents usually have fewer resources to support a move to a higher-status neighbourhood.

It is also important to account for socio-economic characteristics of the origin neighbourhoods - many nest-leavers may try to find accommodation in a neighbourhood that is similar to that of their parents in other respects than ethnic composition. We expect a negative association between house values and average incomes in origin neighbourhoods with the percentage non-westerners in destination neighbourhoods. Furthermore, those whose parental homes are in the large cities of the Netherlands where many non-westerners are concentrated (Amsterdam, Rotterdam, The Hague and Utrecht) will be likely to move to neighbourhoods within these cities. This implies a greater concentration of non-westerners for those from origin neighbourhoods in the large cities.

\section{Data}

We have used data on persons born in 1983 who were living in the parental home in the Netherlands in 1999, derived from an individual administrative panel database that covers the entire population of the Netherlands: the Social Statistical Database (SSD) housed by Statistics Netherlands. The SSD is a set of administrative data registered by local and national institutions such as the tax office, social welfare institutions, municipalities, and institutions for high education. It contains rich information on residential locations and on sociodemographic and socio-economic characteristics. Records of children and their parents are linked, so co-residence between parents and children can be detected. Data were available for the period 1999-2005, with measurement moments on the last Friday of September of each year. So, we were able to follow the entire birth cohort 1983 for the period when they were 16 to 22 years old. The data allow us to track the characteristics of individuals, households and the neighbourhoods in which they live, as well as changes in these variables. Our focus is on those who left the parental home between 1999 and 2005 ${ }^{1}$. For this research population, Table 1 shows descriptive statistics for the variables used in this study by migrant group.

The first variable, the percentage of non-western inhabitants in the destination neighbourhood, is our dependent variable. It is measured at the moment we observe that the young adult has left home. Leaving home can occur between 2000 and 2005 and is measured

\footnotetext{
${ }^{1}$ During this period, about 36 and 59 percent of young men and women, respectively, left the parental home (Zorlu and Mulder, forthcoming). This suggests that we deal with a selective group of young nest leavers. The location choices of older nest leavers may differ from those of the population under study. We checked this proposition using the population of the birth cohort 1977. This exercise indicated a very similar mobility pattern for older nest leavers.
} 
as a change in the young adult's address from living with at least one parent to living away from the parents on the last Friday of September of a given year compared to the previous year. The proportion of non-westerners in the destination neighbourhood is about12 percent for Dutch, between 31 and 34 for Moroccan, Turkish and Surinamese migrants, about 24 for Antillean and other non-western migrants and about15 percent for western migrants. So, nestleavers from the three largest migrant groups (Moroccan, Turkish and Surinamese) seem to be more likely to move to neighbourhoods where non-westerners are strongly concentrated.

The pathway of leaving home is also measured after leaving home. We distinguish three pathways: leaving home to form a union, leaving to live alone independently and leaving to share with anyone else other than a partner. Those leaving for union formation include the small proportion marrying immediately, but are meant also to include those who leave to form an unmarried union. It is impossible to distinguish with certainty those forming unmarried unions from those moving in with roommates. Unfortunately, the decision rules used by Statistics Netherlands to make this distinction based on the absence of a kin relationship, age differences and whether the two persons have a joint child, result in a percentage leaving for union formation that is unrealistically low. It should therefore be borne in mind that part of those registered as leaving for shared accommodation actually form cohabiting unions. The descriptive results indicate that the pathways out of home are slightly different across the ethnic groups. Leaving home for union formation is clearly more common for Turkish and Moroccan young adults compared with other groups. For these two groups, the share of nest leavers for a shared arrangement is correspondingly lower than other groups, whereas the share of home leavers to live alone independently is quite similar across the ethnic groups.

$<<<$ Table 1 about here $>>>$

About a quarter of nest-leavers have a non-Dutch origin, and circa 70 per cent of these were born in the Netherlands from at least one parent who was not born in the Netherlands - the second generation (see Table 1). The fraction of second generation migrants is significantly lower among other non-western migrants, a group that is mainly composed of recent immigrants. The share of the second generation is also relatively low for Antilleans, who are allowed to move between the Netherlands and their home country without any restrictions, because the Antilles are officially part of the Netherlands. Individual and parental characteristics have been measured in the year before leaving home. Income was derived from the tax registers and was measured as the individual taxable income for the young adult and each of his or her parents. The value of the parental home was derived from the official valuation of homes that is used for taxation purposes. Age was measured in years. We experimented with age dummies to check for non-linear effects. The age dummies showed an approximately linear pattern. Neighbourhood characteristics also refer to the situation before leaving home.

As can be seen from Table 1, the average percentage of non-western inhabitants is twice as high in the destination as in the origin neighbourhoods for Dutch nest-leavers, higher for Antillean, Western and other non-Western immigrants, and similar in both neighbourhoods for Moroccans, Turks and Surinamese (for whom the percentage was already large in the origin neighbourhoods). This is not very surprising, because nest-leavers are just starting their housing careers and tend to look for inexpensive housing, frequently in large cities. Whether spatial assimilation takes place can be judged from the association between the concentration of non-western migrants in the destination neighbourhood and the 
concentration in the origin neighbourhood, and the way in which this association differs between the Dutch and non-western migrant groups. We show the shape of this association by ethnic origin and by pathway out of the parental home in Figure 1. We have plotted the fitted association with the 95 percent confidence intervals using a highly flexible functional form, namely a fractional-polynomial function. The horizontal axis in the figures measures the percentage of non-western inhabitants in the origin neighbourhood while the vertical axis measures the percentage non-western in the destination neighbourhood. So, the diagonal line represents an equal non-western concentration in the origin and destination neighbourhoods. When (a part of) the function is below this diagonal line this reflects a tendency for spatial diffusion. If the function is above the diagonal, the tendency is towards neighbourhoods with greater concentrations of non-western migrants.

As expected, the estimates show that the ethnic composition of destination neighbourhoods varies according to the concentration of non-western migrants in the origin neighbourhood. The association between the percentages non-westerners in the origin and destination neighbourhood is positive for nearly all combinations of ethnic origins and pathways of leaving home except Moroccans and Surinamese who leave home for union formation or shared accommodation, where the association is negative for higher percentages of non-westerners in the origin neighbourhood. Probably partly owing to floor and ceiling effects, the fitted functions tend to lie above the diagonal for the lower percentages and below the diagonal for the higher percentages. At first glance, the finding that a larger part of most curves lie below the diagonal seems to suggest spatial diffusion. However, these plots reflect the direction of movers from neighbourhoods with varying ethnic concentration, but they are not informative concerning the net diffusion outcome. It should be borne in mind that many more youth live in and move to neighbourhoods with low than with high percentages of nonwesterners, and so, that there are many observations in the left parts of the graphs where the curves lie above the diagonal, whereas the right parts are based on fewer observations. To show changes in neighbourhood ethnic composition after leaving home, we plot the density of differences between the percentage of non-western migrants in origin and destination neighbourhoods for movers. Figure 2 shows the density functions of the net diffusion for Dutch, Moroccan, Turkish and Surinamese youth, calculated as the fraction of non-western migrants in destination neighbourhood minus the fraction of non-western migrants in origin neighbourhood. The right-hand side of the graph (with positive numbers on the $\mathrm{X}$-axis) indicates net spatial mobility towards ethnic minority neighbourhoods and a tendency of mixing for Dutch, whereas the left-hand side displays a tendency of diffusion for migrants. It is immediately apparent that the net diffusion of migrants is concentrated around zero, whereas the net diffusion of Dutch youth is often positive, indicating a tendency to mix with non-western migrants. In fact, these descriptive results suggest that no diffusion of migrants occurs, given that the overall percentages of non-western migrants are quite similar in the destination and in the origin neighbourhoods (see also Table 1).

$<<<$ Figures 1 and 2 about here $>>>$

\section{Analytical strategy}

\subsection{Regression analysis}

The analysis consists of two parts. First, we try to explain the choice of destination neighbourhood in terms of the proportion of non-western migrants for those who leave the parental home. The location choice of the nest-leavers is modelled to be an outcome of individual and parental socio-economic characteristics and neighbourhood characteristics. 
That is, the percentage of non-western migrants in nest-leaver i's destination neighbourhood, $P_{i}$, is regressed on a vector of individual, parental and neighbourhood demographic and economic variables, $W_{i}$.

$$
P_{i}=W_{i} \beta+\varepsilon_{i}
$$

where $\beta$ is a vector of explanatory variable and $\varepsilon_{i}$ is the error term that is assumed to be normally distributed with mean zero. We apply an OLS estimator.

One may argue that the choice of destination neighbourhood might be associated with the probability of leaving the parental home. To investigate this possible association, we estimated a Heckman selection model ${ }^{2}$, which is a regularly used technique to correct for individual self-selection. This method, however, provided no indication of selectivity of nestleavers. Correspondingly, the results of this selection model were not different from those obtained using an OLS estimator. We therefore only present the results of OLS regressions. The models were estimated for men and women separately. This was done because patterns of leaving home differ markedly between men and women (Zorlu and Mulder, forthcoming).

Technically, the data are not derived from a sample, but from a complete population. However, we believe it still makes sense to present standard errors because the data can be regarded as a one-moment sample from a theoretical population of many time points. The standard errors have been corrected for the clustering of persons in neighbourhoods.

\subsection{Decomposing differentials}

Part of the spatial mobility differentials between Dutch and migrants can be explained by differences in the characteristics of Dutch and immigrants that are included in the models. Of the unexplained part, an unknown proportion may be attributed to discrimination and/or preferences. In the second part of our analysis, we aim to assess the native-immigrant differentials in destination neighbourhood choice. We use the linear decomposition technique (Oaxaca, 1973; Blinder, 1973) to decompose the differences in the mean percentages of nonwestern migrants in the destination neighbourhoods of Dutch and migrant nest-leavers into explained and unexplained parts. This Oaxaca-Blinder technique is widely used in the economic literature to decompose wage and employment differentials between ethnic groups or between men and women into explained and unexplained components. For the analysis, we clustered the immigrants into five groups: Moroccan, Turkish, Surinamese, other non-western and western migrants, $m=1,2, . ., 5$, and estimated separate regression models for these groups and native Dutch (the models themselves are not shown).

Suppose the percentages of non-western migrants in the destination neighbourhoods of Dutch and migrant group $m$ are given by the following regression functions:

Dutch: $\quad P_{D i}=W_{D i} \beta_{D}+\varepsilon_{D i}$

Migrant group $m: \quad P_{m i}=W_{m i} \beta_{m}+\varepsilon_{m i}, \quad$ with $m=1,2, . ., 5$

where $P$ is the percentage of non-western migrants in the destination neighbourhood, with the subscripts $D$ and $m$ denoting Dutch and migrants, $W_{i}$ is a vector of relevant observed

\footnotetext{
${ }^{2}$ The Heckman selection model was estimated using the same variables as in our OLS in the outcome equation and a number of additional variables in the selection equation that are thought to be exogenous to the choice of the destination neighbourhood, such as the age difference between the parents and the number of adults and children in the household.
} 
characteristics, $\beta$ is a vector of coefficients to be estimated and $\varepsilon_{i}$ is the randomly distributed error term.

Formally, the Oaxaca-Blinder technique decomposes the observed mean differential of the percentage of natives in the destination neighbourhood, $\bar{P}_{D}-\bar{P}_{m}$, into two components by means of the following equation:

$$
\bar{P}_{D}-\bar{P}_{m}=\hat{\beta}_{D}\left(\bar{X}_{D}-\bar{X}_{m}\right)+\bar{X}_{m}\left(\hat{\beta}_{D}-\hat{\beta}_{m}\right)
$$

where $\bar{X}_{D}$ and $\bar{X}_{m}$ are the mean values for the regressors, and $\hat{\beta}_{D}$ and $\hat{\beta}_{m}$ are the associated coefficients. The first term on the right hand side, $\hat{\beta}_{D}\left(\bar{X}_{D}-\bar{X}_{m}\right)$, is a differential owing to the observed characteristics and the second term $\bar{X}_{m}\left(\hat{\beta}_{D}-\hat{\beta}_{m}\right)$ gives unexplained differentials.

This decomposition technique is highly sensitive to the choice of the reference group, whose outcome is not affected by unobserved factors. In other words, in the context of this study, the reference group has an indifferent preference structure or a non-discriminatory choice structure regarding the choice of the ethnic composition of the destination neighbourhood. In the original form of the decomposition, Oaxaca (1973) proposed either a male or female sample as the reference group. Neumark (1988) and Oaxaca and Ransom (1994) show that the extent of the unexplained part is sensitive to the choice of a nondiscriminatory structure. Later studies suggest a non-discriminatory structure $\beta^{*}$ be estimated, so that (4) becomes

$$
\bar{P}_{D}-\bar{P}_{m}=\hat{\beta}_{D}\left(\bar{X}_{D}-\bar{X}_{m}\right)+\left\lfloor\bar{X}_{D}\left(\hat{\beta}_{D}-\beta^{*}\right)+\bar{X}_{m}\left(\beta^{*}-\hat{\beta}_{m}\right)\right\rfloor
$$

where the estimated non-discriminatory structure is given as

$$
\beta^{*}=\Omega \hat{\beta}_{D}+(I-\Omega) \hat{\beta}_{m}
$$

Cotton (1988) suggests a weighting matrix $(\Omega)$ reflecting the share of the majority group in the sample $\left(I_{n}\right), \Omega=I_{n} I$. Alternatively, Neumark (1988) proposes a least-squares criterion to estimate a weighting matrix from the pooled sample of all the distinguished groups, $\beta^{*}=\left(X^{\prime} X\right)^{-1}\left(X^{\prime} P\right)=\hat{\beta}$, where $X$ is the observation matrix, $P$ is the observation vector of the response variable and $\hat{\beta}$ is the OLS estimate obtained from the pooled sample. In other words, a common preference structure derived from the pooled sample of natives and immigrants is assumed to represent an indifferent preference structure. This approach implies that natives and ethnic minorities contribute to an indifferent preference structure according to their weighted share in the entire population. We adopt this approach because of its more realistic nature.

The decomposition is implemented as follows. First, the equations for the Dutch and the separate immigrant groups are estimated. After estimating the equations, the explained and unexplained differentials between the Dutch and migrant group $m$ can be calculated using the estimated coefficients and the means of variables as shown in equation (5). The indifferent preference structure $\left(\beta^{*}\right)$ is obtained from an estimation of a pooled model for Dutch and migrant groups together.

\section{Results}

\subsection{Results of the OLS estimations}


The parameter estimates of the linear regression model (1) are shown in Table 2, for men and women separately. After controlling for individual and parental background and neighbourhood characteristics, the percentage of non-western inhabitants in the destination neighbourhood is higher for migrant groups than for Dutch, the reference group. The percentage non-western in the destination neighbourhood is lowest for western migrants and highest for Moroccans, followed by Turkish, Surinamese, other non-western and Antillean migrants. The rank orders are similar for migrant men and women, although migrant women are more likely than migrant men to move to a neighbourhood with many immigrants. Interestingly, even after controlling for socio-economic background, this rank order of countries of origin in the inclination to move to areas with greater non-western concentrations reflects the typical rank order in the socio-economic positions of these immigrant groups (Zorlu \& Hartog, 2008).

As expected, second-generation migrants tend to move to neighbourhoods with fewer non-western immigrants, although this association is not statistically significant for men. Furthermore, those second generation migrants with a mixed ethnic background tend to move to neighbourhoods with even fewer non-western immigrants than those second-generation migrants with two immigrant parents.

Students are more likely to move to neighbourhoods with higher concentrations of non-western migrants, possibly owing to the presence of affordable housing in these neighbourhoods. The inclination of students to move to immigrant neighbourhoods is greater for men than for women. Young adults with a job and whose parents were living in a more expensive house seem to avoid immigrant neighbourhoods. This holds more strongly for women than for men. Surprisingly, after controlling for these socio-economic characteristics there is no statistically significant impact of the young adult's income and, for men, owneroccupancy of the parents' home is associated with a higher rather than a lower percentage of non-western immigrants.

Different pathways out of the parental home are associated with different neighbourhood types. Those who leave home for union formation tend to move to neighbourhoods with fewer immigrants, whereas leaving home for a shared living arrangement is associated with a higher degree of immigrant concentration than leaving for an independent living arrangement.

There is no statistically significant association with the household situation of the parents. The impact of parental income is positive, rather than negative as was expected. This positive effect may stem from a greater inclination of nest leavers from wealthier families in suburban areas to move to large cities for reasons of education, where many neighbourhoods are coloured by migrants. Our controls for the four largest cities might not have completely captured the effect of large cities as destinations.

Naturally, there is a strong positive effect of the percentage non-western in the origin neighbourhood. To check for variations in the effect of concentrations of non-western in the origin neighbourhood across ethnic groups, we have interacted migrant-group fixed effects with the percentage non-western in the origin neighbourhood. The estimates revealed that the correlation between the ethnic composition of origin and destination neighbourhood was stronger for Turkish and Moroccans than for other migrant groups. This result suggests that Turkish and Moroccan nest-leavers are particularly likely to remain in their neighbourhood of origin or move to a similar neighbourhood, whereas this tendency is weaker for Surinamese and other non-western migrants. This result is confirmed by results from separate regression analyses for the Dutch and the five different immigrant groups (not shown) and the decomposition analysis reported in the next section. 
As expected, nest-leavers from the four largest cities tend to move to neighbourhoods with more non-western migrants. This high correlation is possibly a result of the fact that many remain within their city of origin. Contrary to expectations, better economic conditions in the origin neighbourhood seem to be positively associated with the percentage of immigrants in the destination neighbourhood.

All in all, it is striking that several socio-economic variables have only modest effects or effects in an unexpected direction. In contrast, individual immigrant origin and neighbourhood characteristics related to ethnicity have marked effects on neighbourhood choice. These results suggest that the choice of destination neighbourhood is not just a matter of socio-economic factors, but that ethnicity has an important impact on location choice. Particularly the strong effect of immigrant origin on the percentage of non-western migrants in the destination neighbourhood might well be a sign of ethnically specific preferences or discrimination.

$<<<$ Table 2 about here $>>>$

\subsection{Results of the decomposition analyses}

From the regression results, we get an impression of the effects of the independent variables under ceteris paribus conditions. But to evaluate which part of the ethnic differences in the composition of the destination neighbourhood is attributable to background variables and which part is not, a decomposition analysis is needed. Table 3 shows the results of this analysis. The explained component refers to the contribution of the variables in the separate regression models for the ethnic groups. Among these variables, the proportion of nonwestern migrants in the origin neighbourhood explains more than half of the total difference between most migrant groups and Dutch, and more than three quarters of the explained difference. We therefore also present the separate contribution of this variable to the explanation of the difference.

The difference in the percentage of non-western migrants in the destination neighbourhoods of Turkish and Dutch young adults is estimated at 18.4 for men and 19.4 for women. These differences are large given the mean percentage (16.4 for men and 14.8 for women). More than 80 percent of these differences (13.8 and 13.4 percentage points) is explained by the observed characteristics, but particularly by the ethnic composition of the origin neighbourhood (about 12 percentage points). The difference between Moroccans and Dutch is even greater than between Turkish and Dutch. Of the 19.8 and 22.5 percentage points differences for men and women, 15.1 and 16.0 are explained by the observed characteristics, of which about 12 by the percentage non-western in the origin neighbourhood.

The differences between Surinamese and Dutch are quite similar to those between Turkish and Dutch. About half of the 18.8 and 21.6 percentage points differences for men and women are explained by the ethnic composition of the origin neighbourhood and somewhat more than a quarter is not explained by the observed characteristics. Young adults with an 'other' non-western background move to neighbourhoods with a lower percentage of nonwestern migrants, compared to the three largest migrant groups. The difference between this category and the Dutch is about 12 percentage points, of which almost the half is explained by the ethnic composition of the origin neighbourhood. The migrant - native difference in the ethnic composition of the destination neighbourhood is smallest for western migrants: 2.9 percentage points for men and 3.3 for women.

$<<<$ Table 3 about here $>>>$ 


\section{Conclusions}

Leaving the parental home is an important step to independence for young adults. This step can have additional implications for migrant young adults who grow up within immigrant households and frequently in immigrant neighbourhoods. For them, leaving home may or may not be an occasion for spatial assimilation into the mainstream society. In this paper we compared the location choices of migrant and Dutch nest-leavers with regard to the ethnic composition of the neighbourhood where they move to upon leaving home. This was possible due to the Social Statistical Database, a dataset covering the entire population of the Netherlands. This dataset has the enormous advantage of large numbers and the absence of non-response and panel attrition.

The analysis shows that nest-leavers with a migrant background from Morocco, Turkey, Surinam, the Netherlands Antilles and other non-western countries move to neighbourhoods where the proportion of non-western migrants is substantially higher than in the neighbourhoods Dutch nest-leavers move to. These differences can be attributed only for a very small part to differences in socio-economic characteristics of the nest-leavers, their parents or their origin neighbourhoods.

About three quarters of the differences between the various migrant groups and the Dutch in the percentage of non-western migrants in the destination neighbourhood are explained from differences in observed characteristics, among which the ethnic composition of the origin neighbourhood is a dominant factor. The percentage of non-western migrants in the origin neighbourhood of nest-leavers makes up about 85 percent of the explained difference for Turkish young adults and about 71 to 76 percent for Surinamese and Moroccan young adults. The strong predictive power of the origin location for the choice of the destination neighbourhood may simply reflect the fact that many nest-leavers stay close to their parental home. This tendency to remain close, or possibly also to move to neighbourhoods farther away that are similar to the origin neighbourhood, may partly stem from ethnic social networks. In the remaining unexplained difference (which is 25 to 30 percent of the total difference between migrant groups and Dutch), preferences and discrimination in the housing market likely play an important part.

A striking finding is the consistently larger differences between migrants and Dutch among women than among men. The unexplained difference measured in percentage points is also consistently larger for women than men. This might indicate that preferences of migrant women lead to a greater segregatory tendency, at least if possible discrimination and other unobserved characteristics affect migrant men and women in a similar way. One may think that migrant female nest-leavers might be forced or encouraged by their family to remain in migrant neighbourhoods close to their parents in accordance with cultural norms that may be stronger for women than for men. Unfortunately, our data do not allow us to assess whether this speculation might be true.

Despite the important advantages of the dataset, it is not without problems either. One of these problems is a likely under-estimation of unmarried cohabitation, which occurs among our specific population of nest-leavers despite a credible approximation of the level of cohabitation in the total population of the Netherlands. It is also unfortunate that the data on level of education are incomplete. No data are available on undocumented migrants. Furthermore, we cannot be certain that all nest-leavers register their change of address correctly, even though they are obliged to do so promptly by Dutch law. 
We have focused on only one aspect of location choice: the share of non-western immigrants and their descendants in the destination neighbourhood. Although this is an important aspect because of its consequences for segregation, our analysis does not reveal much about where the nest-leavers actually move to or how far away they end up from their parents. Further research could address such other aspects of the location choices of nestleavers. Another interesting topic for further research is the location choice of nest-leavers originating from particular neighbourhoods, for example neighbourhoods with high proportions of non-western migrants.

All in all, no clear intergenerational break of spatial diffusion is observed for migrant young adults when they leave the parental home. There is only very limited evidence that migrant youth with a better socio-economic position tend to move to less segregated neighbourhoods. The strong association between the ethnic concentrations in origin and destination neighbourhoods and the large differences between the migrant groups and the Dutch suggest a strong inter-generational continuity in neighbourhood choice. However, after accounting for their ethnic backgrounds migrant young adults from the second generation tend to move to somewhat less segregated neighbourhoods than Dutch, and those with one Dutch parent move to neighbourhoods with substantially smaller concentrations of nonwesterners. This result provides some evidence for at least one prediction derived from spatial assimilation theory. Possibly, spatial assimilation will accelerate among later generations.

Acknowledgments: This research is supported by the Netherlands Organisation for Scientific Research (NWO), VICI grant no. 453-04-001. The paper is part of a joint project with Statistics Netherlands; we are grateful to the Department of Socio-Economic State for allowing us the use of the Social-Statistical Database (SSD).

\section{References}

Alba, R.D. \& Logan, J. (1993). Minority proximity to whites in suburbs: An individual-level analysis of segregation. American Journal of Sociology, 98, 1388-1427.

Blinder, A. S. (1973). Wage Discrimination: Reduced Form and Structural Estimates, Journal of Human Resources, 8, 436-455.

Bernhardt, E., C. Goldscheider, F. Goldscheider, \& Bjeren, G. (2007). Immigration, gender and family transitions to adulthood in Sweden. Lanham: University Press of America, Inc.

Bolt, G. (2002). Turkish and Moroccan couples and their first steps on the Dutch housing market: Co-residence or independence? Journal of Housing and the Built Environment, 17, 269-292.

Card, D., Mas, A. \& Rothstein, J. (2008). Tipping and the Dynamics of Segregation. The Quarterly Journal of Economics, 123, 1, 177-218

Cotton, J. (1988). On the decomposition of wage differentials. Review of Economics and Statistics, 70, 236-243.

Clark, W. A. V. (1991). Residential preferences and neighborhood racial segregation: A test of the Schelling segregation model. Demography, 28, 1-19.

Clark, W. A. V. (1992). Residential preferences and residential choices in a multiethnic context, Demography, 29, 451-466.

Cutler, D. M., Glaeser, E.L. \& Vigdor J.L. (1999). The rise and decline of the American ghetto. Journal of Political Economy, 107, 455-506. 
Dawkins, C. J. (2006). Are social networks the ties that bind families to neighborhoods? Housing Studies, 21, 867-881.

De Valk, H. A. G., \& Billari, F. C. (2007). Living arrangements of migrant and Dutch young adults: The family influence disentangled. Population Studies, 61, 201-217.

Farley, R., Schuman, H., Bianchi, S., Colasanto, D. \& Hatchett, S. (1978). Chocolate city, vanilla suburbs: Will the trend toward racially separate communities continue? Social Science Research, 7, 319-344.

Farley, R., Steeh, C.G., Krysan, M., Reeves, K. \& Jackson, T. (1994). Stereotypes and segregation: Neighbourhoods in Detroit area. American Journal of Sociology, 100, 750-778.

Galster, G. C. (1990). Neighborhood racial change, segregationist sentiments, and affirmative marketing policies. Journal of Urban Economics, 27(3), 344-361,

Glick, J. E., \& Van Hook, J. (2002). Parents' coresidence with adult children: Can immigration explain racial and ethnic variation? Journal of Marriage and Family, 64, 240-253.

Gross, A.B. \& Massey, D.S. (1991). Spatial Assimilation Models: A Micro-Macro Comparison. Social Science Quarterly, 72, 347-360.

Kempen, R. van \& Özüekren, A.S. (1998). Ethnic segregation in cities: new forms and explanations in a dynamic world. Urban studies, 35, 1631-1656.

Massey, D.S. (1985). Ethnic Residential Segregation: a Theoretical Synthesis and Empirical Review. Sociology and Social Research, 69, 315-350.

Massey, D.S. \& Denton, N.A. (1985) Spatial Assimilation as a Socioeconomic Outcome. American Sociological Review, 50, 94-106.

Mulder, C. H., \& Clark, W. A. V. (2000). Leaving home and leaving the state: Evidence from the United States. International Journal of Population Geography, 6, 423-437.

Musterd, S. (2005). Social and ethnic segregation in Europe: Levels, causes, and effects. Journal of Urban Affairs, 27, 331-348.

Musterd, S. \& Vos, S. de (2007). Residential dynamics in ethnic concentrations. Housing Studies, 22, 3, 333-353.

Neumark, D. (1988). Employers' discriminatory behavior and the estimation of wage discrimination. Journal of Human Resources, 23, 279-295.

Nilsson, K., \& Strandh, M. (1999). Nest leaving in Sweden: The importance of early educational and labor market careers. Journal of Marriage and the Family, 61, 10681079.

Oaxaca, R. (1973). Male-female wage differentials in urban labor markets. International Economic Review, 14, 693-709.

Oaxaca, R. L. \& Ransom, M.R. (1994). On discrimination and the decomposition of wage differentials. Journal of Econometrics, 61, 5-21.

Portes, A. and Zhou, M. (1993). The New Second Generation: Segmented Assimilation and its Variants. The annals of the American Academy of Political and Social Science, 530, 1, 74-96

Schelling, T. C. (1971). Dynamic models of segregation. Journal of Mathematical Sociology, $1,143-186$.

Simpson, L. (2004). Statistics of racial segregation: measures, evidence and policy. Urban Studies, 14, 3, 661-681.

South, S.J. \& Crowder, K.D. (1997a). Escaping distressed neighborhoods: Individual, community, and metropolitan influences. American Journal of Sociology, 102, 10401084.

South, S.J., Crowder, K. \& Chavez, E. (2005). Migration and Spatial assimilation among U.S. Latinos: classical versus segmented trajectories. Demography, 42, 497-521. 
Spilimbergo, A. \& Ubeda, L. (2004). Family attachment and the decision to move by race. Journal of Urban Economics, 55, 478-497.

Zhou, M., \& Logan, J.R. (1991). In and out of Chinatown: Residential mobility and segregation of New York City's Chinese. Social Forces, 70,2, 387-407.

Zorlu, A. \& Latten, J. (2009). Ethnic sorting in the Netherlands. Urban Studies, 46, 18991923.

Zorlu, A. \& J. Hartog (2008). Employment assimilation of immigrants in the Netherlands : catching up and the irrelevance of education. IZA Discussion paper, 3534

Zorlu, A. (2008). Who leaves the city? The influence of ethnic segregation and family ties. IZA Discussion Paper, 3343.

Zorlu, A. \& Mulder, C.H. (forthcoming). Ethnic differences in leaving home: Timing and pathways. Demography. 
Table 1

Descriptive statistics of the study population

\begin{tabular}{|c|c|c|c|c|c|c|c|}
\hline & Dutch & Moroc. & Turkish & Surinam & Antillean & Oth N-W & Western \\
\hline $\begin{array}{l}\text { \% Non Western in destination neighbourhood } \\
\text { Pathways out of home }\end{array}$ & 12.24 & 33.52 & 31.25 & 32.65 & 24.19 & 24.51 & 15.39 \\
\hline Moved to form a union & 0.04 & 0.09 & 0.14 & 0.03 & 0.01 & 0.03 & 0.02 \\
\hline Moved to shared accommodation & 0.45 & 0.40 & 0.33 & 0.47 & 0.48 & 0.43 & 0.44 \\
\hline Moved to live independently & 0.51 & 0.51 & 0.53 & 0.50 & 0.50 & 0.55 & 0.54 \\
\hline \multicolumn{8}{|l|}{ Immigrant generation } \\
\hline First generation & & 0.35 & 0.21 & 0.24 & 0.47 & 0.57 & 0.20 \\
\hline 2nd generation & & 0.62 & 0.76 & 0.60 & 0.18 & 0.22 & 0.11 \\
\hline 2nd generation (Mixed) & & 0.03 & 0.03 & 0.16 & 0.35 & 0.21 & 0.69 \\
\hline \multicolumn{8}{|l|}{ Individual characteristics } \\
\hline Age & 20.12 & 18.96 & 18.87 & 19.50 & 19.71 & 19.69 & 19.94 \\
\hline In education & 0.62 & 0.77 & 0.75 & 0.68 & 0.63 & 0.72 & 0.67 \\
\hline Employed & 0.40 & 0.25 & 0.27 & 0.28 & 0.28 & 0.26 & 0.33 \\
\hline Log income & 5.43 & 4.00 & 3.75 & 4.17 & 4.41 & 4.56 & 4.95 \\
\hline Parents' home owner-occupied & 0.72 & 0.03 & 0.16 & 0.29 & 0.31 & 0.27 & 0.57 \\
\hline Log value of dwelling & 11.21 & 11.06 & 10.80 & 10.69 & 11.07 & 10.96 & 11.18 \\
\hline \multicolumn{8}{|l|}{ Parents' household situation } \\
\hline Mother unmarried & 0.03 & 0.00 & 0.00 & 0.18 & 0.24 & 0.04 & 0.04 \\
\hline Mother widowed & 0.02 & 0.03 & 0.03 & 0.02 & 0.01 & 0.03 & 0.03 \\
\hline Mother divorced & 0.14 & 0.08 & 0.12 & 0.41 & 0.28 & 0.23 & 0.23 \\
\hline \multicolumn{8}{|l|}{ Parents economic situation } \\
\hline Log income mother & 11.22 & 4.80 & 7.52 & 14.52 & 13.24 & 9.91 & 12.27 \\
\hline Log income father & 29.71 & 12.51 & 15.17 & 14.24 & 15.14 & 14.16 & 24.67 \\
\hline \multicolumn{8}{|l|}{ Local conditions in origin neigbourhood } \\
\hline \% Non-western in neighbourhood & 6.51 & 33.47 & 31.91 & 32.36 & 20.88 & 21.17 & 9.95 \\
\hline Log average house value in neighbourhood & 11.79 & 11.43 & 11.37 & 11.39 & 11.53 & 11.54 & 11.74 \\
\hline Log average income in neighbourhood & 5.64 & 8.39 & 8.31 & 6.96 & 6.69 & 6.76 & 6.21 \\
\hline Amsterdam & 0.01 & 0.22 & 0.11 & 0.21 & 0.08 & 0.09 & 0.04 \\
\hline Rotterdam & 0.02 & 0.12 & 0.15 & 0.18 & 0.13 & 0.11 & 0.04 \\
\hline The Hague & 0.02 & 0.09 & 0.09 & 0.14 & 0.06 & 0.05 & 0.03 \\
\hline Utrecht & 0.01 & 0.07 & 0.04 & 0.02 & 0.01 & 0.01 & 0.01 \\
\hline $\mathrm{N}$ & 67415 & 3883 & 3640 & 2869 & 960 & 3297 & 6216 \\
\hline
\end{tabular}




\section{Table 2}

OLS estimates of the percentage of non-western migrants in the destination neighbourhood.

\begin{tabular}{|c|c|c|c|c|c|}
\hline \multirow[t]{2}{*}{ Variables } & \multicolumn{2}{|l|}{ Men } & \multicolumn{3}{|l|}{ Women } \\
\hline & Coeff. & $\mathrm{SE}$ & Coeff. & & SE \\
\hline \multicolumn{6}{|l|}{ Immigrant origin } \\
\hline Moroccan & 8.103 & $* * * 0.570$ & 10.772 & $* * *$ & 0.534 \\
\hline Turkish & 7.868 & *** 0.599 & 9.742 & $* * *$ & 0.538 \\
\hline Surinamese & 6.206 & $* * * 0.704$ & 9.387 & $* * *$ & 0.608 \\
\hline Antillean & 5.378 & $* * * 0.913$ & 6.841 & $* * *$ & 0.789 \\
\hline Other non-western & 6.191 & $* * * 0.494$ & 6.427 & $* * *$ & 0.468 \\
\hline Western & 3.172 & $* * * 0.476$ & 3.713 & $* * *$ & 0.414 \\
\hline 2nd generation & -0.350 & 0.478 & -1.041 & $*$ & 0.436 \\
\hline 2nd generation (Mixed) & -2.716 & $* * * 0.504$ & -3.064 & $* * *$ & 0.432 \\
\hline \multicolumn{6}{|l|}{ Individual characteristics } \\
\hline Age & 1.165 & $* * * 0.108$ & 0.588 & $* * *$ & 0.083 \\
\hline In education & 3.155 & $* * * 0.241$ & 1.711 & $* * *$ & 0.196 \\
\hline Employed & -0.400 & 0.256 & -0.799 & $* * *$ & 0.203 \\
\hline Log income & 0.027 & 0.041 & -0.011 & & 0.034 \\
\hline Owner occupied & 0.784 & $* * * 0.187$ & 0.083 & & 0.138 \\
\hline Log value of home & -0.040 & 0.028 & -0.015 & & 0.023 \\
\hline \multicolumn{6}{|l|}{ Pathway of leaving home } \\
\hline Moved to form a union & -2.543 & $* * * 0.401$ & -2.121 & $* * *$ & 0.250 \\
\hline Moved to live in shared accommodation & 0.386 & * $\quad 0.157$ & -0.261 & $*$ & 0.124 \\
\hline \multicolumn{6}{|l|}{ Parents' household situation } \\
\hline Mother unmarried & 0.421 & 0.471 & 0.661 & & 0.405 \\
\hline Mother widow & 0.520 & 0.552 & -0.582 & & 0.419 \\
\hline Mother divorced & -0.016 & 0.227 & -0.058 & & 0.184 \\
\hline \multicolumn{6}{|l|}{ Parents' economic situation } \\
\hline Income mother & 0.017 & * $\quad 0.007$ & 0.037 & $* * *$ & 0.006 \\
\hline Income father & 0.021 & $* * * 0.004$ & 0.029 & $* * *$ & 0.003 \\
\hline \multicolumn{6}{|l|}{ Characteristics of origin neighbourhood } \\
\hline \% Non-western & 0.375 & $* * * 0.011$ & 0.365 & $* * *$ & 0.009 \\
\hline Log average house value in neighbourhood & 0.896 & $* * * 0.173$ & 0.713 & $* * *$ & 0.148 \\
\hline Log average income in neighbourhood & 0.181 & $* * * 0.029$ & 0.119 & $* * *$ & 0.022 \\
\hline Amsterdam & 9.758 & $* * * 0.561$ & 7.491 & $* * *$ & 0.480 \\
\hline Rotterdam & 10.786 & $* * * 0.580$ & 10.005 & $* * *$ & 0.483 \\
\hline The Hague & 9.440 & $* * * 0.686$ & 8.084 & $* * *$ & 0.577 \\
\hline Utrecht & 3.280 & $* * * 0.836$ & 3.573 & $* * *$ & 0.681 \\
\hline Constant & -27.871 & $* * * 2.947$ & -13.680 & $* * *$ & 2.382 \\
\hline R-squared & 0.33 & & 0.33 & & \\
\hline $\mathrm{N}$ & 35101 & & 52944 & & \\
\hline
\end{tabular}

${ }^{*} \mathrm{p}<0.05 ;{ }^{* *} \mathrm{p}<0.01 ; * * * \mathrm{p}<0.001$

Note: the standard errors have been corrected for the clustering of individuals in neighbourhoods 
Table 3

Decomposition of differences in percentage non-western in the destination neighbourhood

\begin{tabular}{|c|c|c|c|c|}
\hline & \multicolumn{2}{|c|}{ Men } & \multicolumn{2}{|c|}{ Women } \\
\hline & Coefficient & Std Err & Coefficient & Std Err \\
\hline \multicolumn{5}{|l|}{ Turkish - Dutch } \\
\hline Difference & 18.42 & 0.54 & 19.41 & 0.50 \\
\hline Explained & 13.79 & 0.42 & 13.40 & 0.38 \\
\hline \% non-western in origin neighbourhood & 12.10 & 0.40 & 11.49 & 0.35 \\
\hline Not explained & 4.63 & 0.30 & 6.01 & 0.30 \\
\hline \multicolumn{5}{|l|}{ Moroccan - Dutch } \\
\hline Difference & 19.77 & 0.52 & 22.51 & 0.50 \\
\hline Explained & 15.14 & 0.41 & 16.00 & 0.38 \\
\hline \% non-western in origin neighbourhood & 11.56 & 0.40 & 12.11 & 0.36 \\
\hline Not explained & 4.63 & 0.29 & 6.52 & 0.31 \\
\hline \multicolumn{5}{|l|}{ Surinamese - Dutch } \\
\hline Difference & 18.79 & 0.68 & 21.56 & 0.56 \\
\hline Explained & 13.53 & 0.47 & 14.62 & 0.39 \\
\hline \% non-western in origin neighbourhood & 9.94 & 0.44 & 10.42 & 0.37 \\
\hline Not explained & 5.26 & 0.48 & 6.95 & 0.42 \\
\hline \multicolumn{5}{|l|}{ Other non-western - Dutch } \\
\hline Difference & 12.17 & 0.54 & 12.24 & 0.50 \\
\hline Explained & 7.27 & 0.33 & 7.24 & 0.29 \\
\hline \% non-western in origin neighbourhood & 5.98 & 0.29 & 5.68 & 0.25 \\
\hline Not explained & 4.90 & 0.39 & 5.00 & 0.39 \\
\hline \multicolumn{5}{|l|}{ Western - Dutch } \\
\hline Difference & 2.89 & 0.31 & 3.30 & 0.25 \\
\hline Explained & 1.46 & 0.13 & 1.80 & 0.10 \\
\hline$\%$ non-western in origin neighbourhood & 1.15 & 0.10 & 1.24 & 0.08 \\
\hline Not explained & 1.43 & 0.29 & 1.51 & 0.23 \\
\hline
\end{tabular}




\section{Figure 1}

Non-parametric estimation of the choice of the destination neighbourhood

Dutch \& Turkish

Union

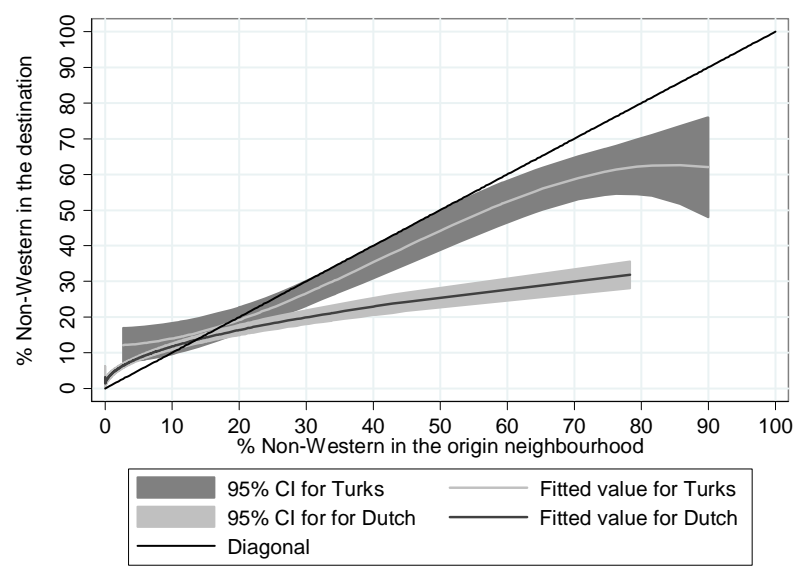

Independent

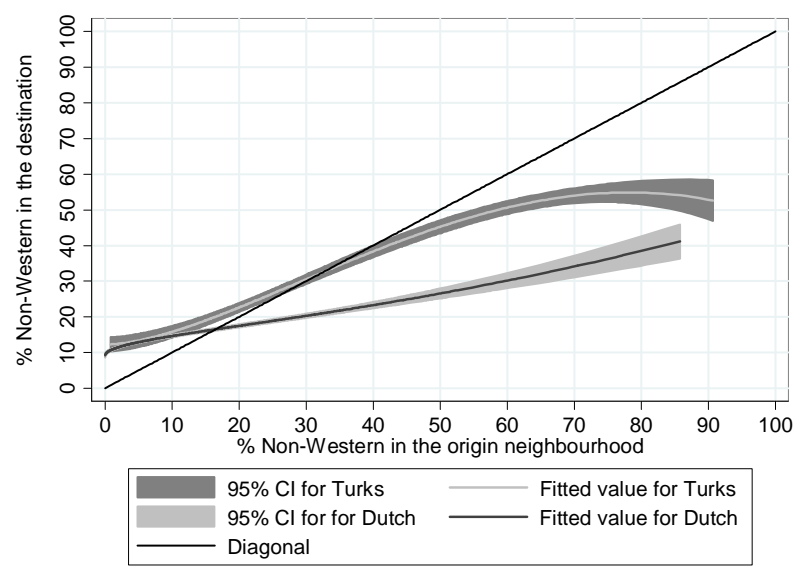

Shared

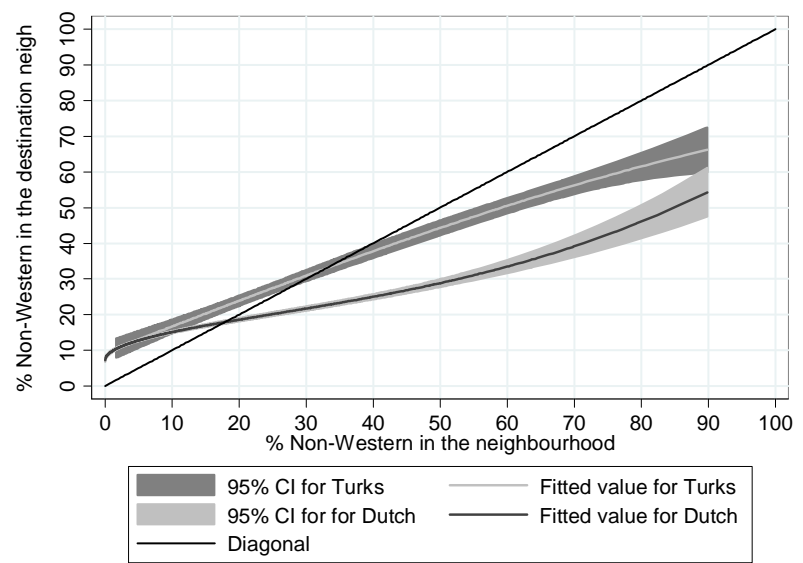

\section{Moroccans \& Surinamese} Union

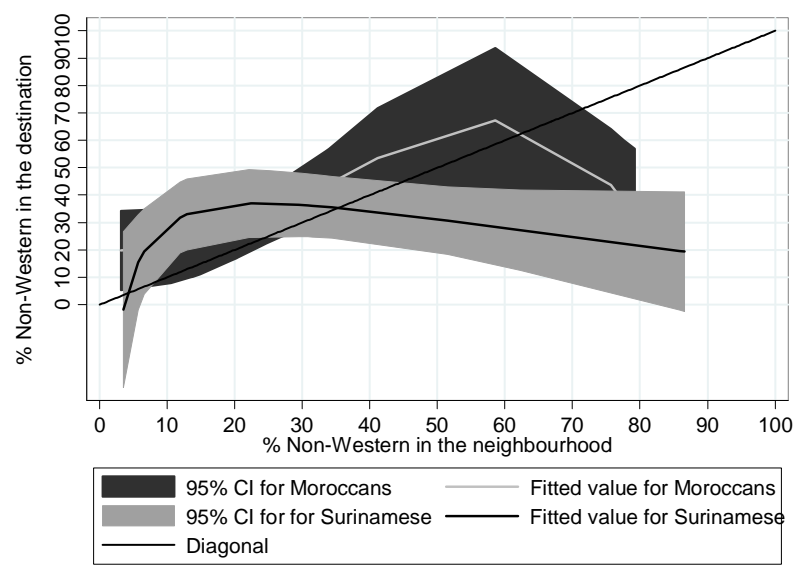

Independent

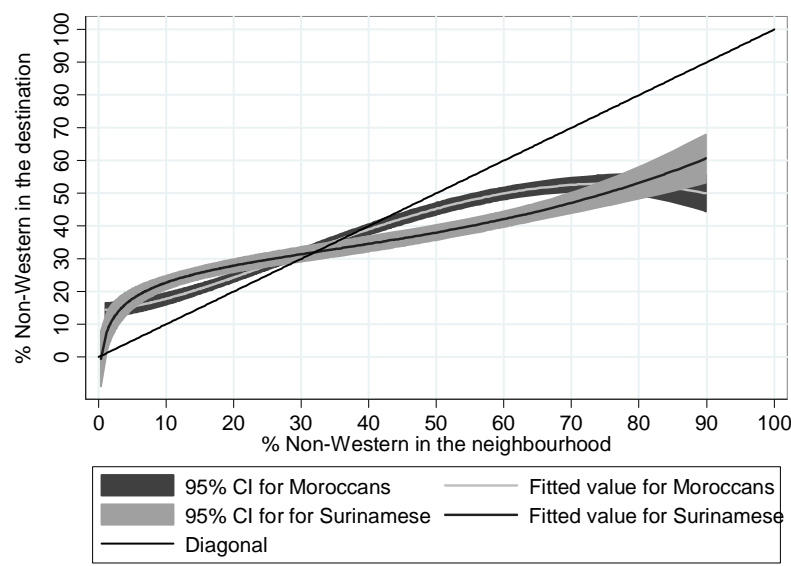

Shared

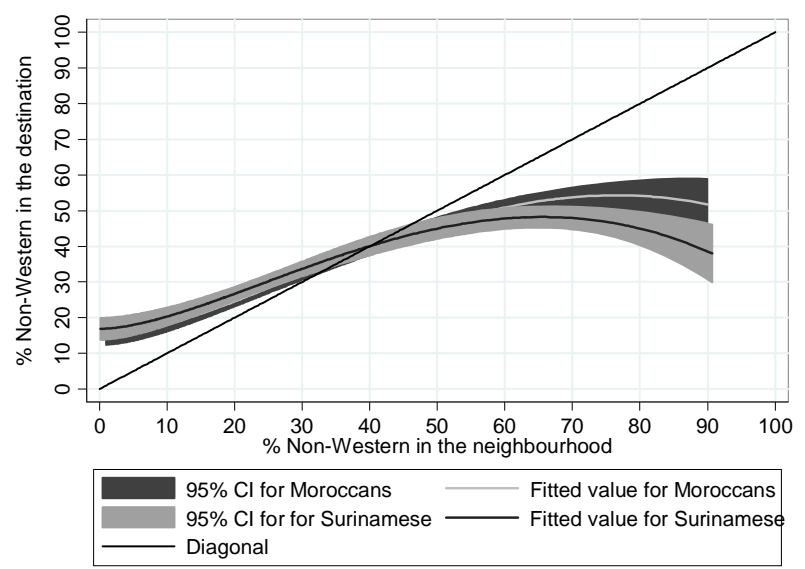

Note that the bands along the curves are confidence intervals 


\section{Figure 2}

Density function of spatial diffusion at leaving home, by ethnic background

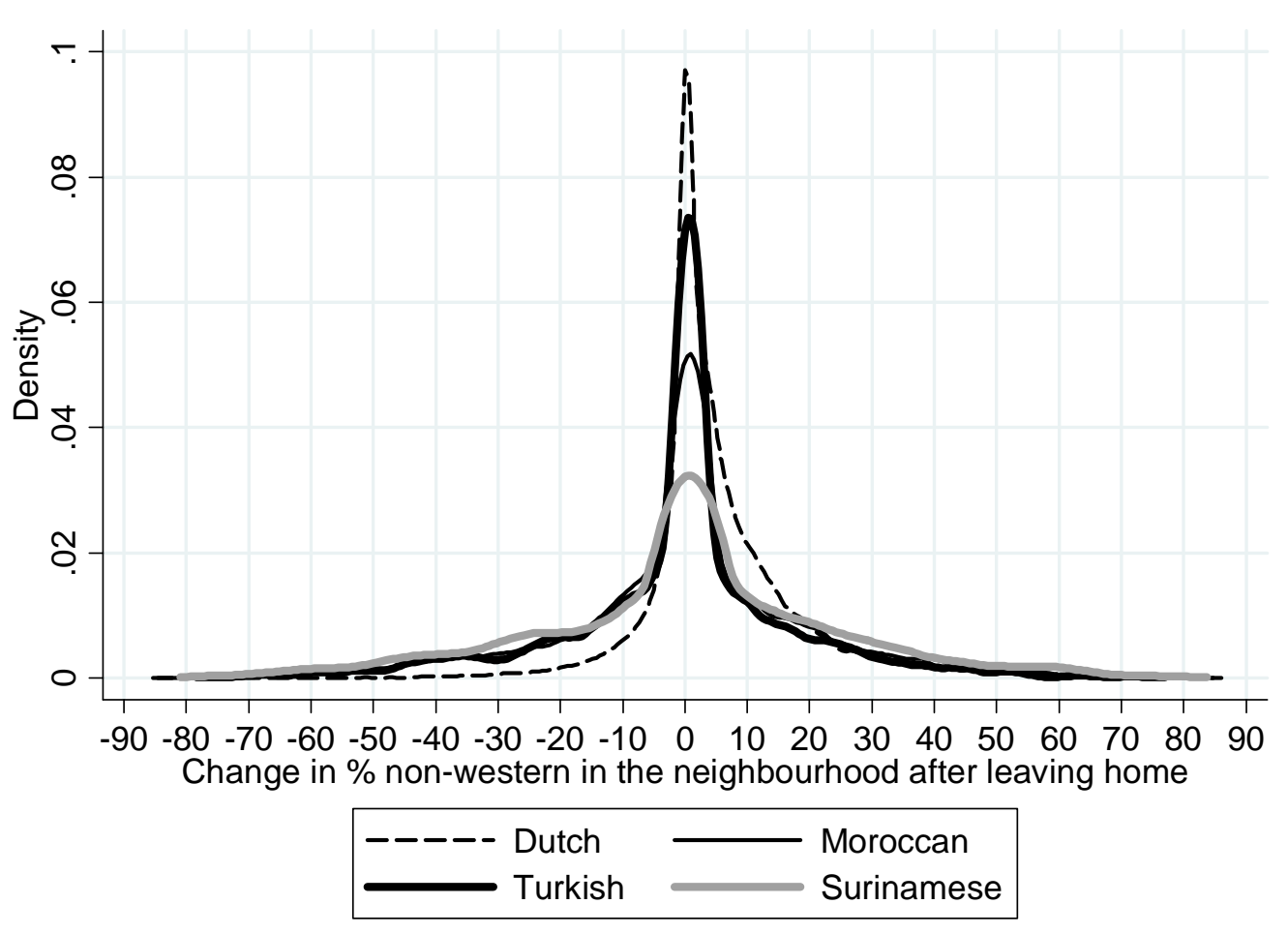

